\title{
Transformation of metal speciation in purple soil as affected by waterlogging
}

\author{
S. A. Zheng $\cdot$ X. Q. Zheng $\cdot$ C. Chen
}

Received: 18 June 2011/Revised: 12 January 2012/Accepted: 18 March 2012/Published online: 19 December 2012

(c) CEERS, IAU 2012

\begin{abstract}
This study was conducted to investigate the effect of waterlogging on copper, lead and cadmium fractionation in Chinese purple soil. Heavy metals were added to purple soil at $80 \%$ field capacity and waterlogging regimes as nitrate salts of $500 \mathrm{mg} \mathrm{kg}^{-1}$ of copper and lead, and $5 \mathrm{mg} \mathrm{kg}^{-1}$ of cadmium. Metals in the incubated soil samples were fractionated termly from 1 to 35 days by the sequential extraction procedure. Under both treatments, the heavy metals spiked in the soil were transformed slowly from the exchangeable fractions into more stable fractions, whereas their residual fractions barely changed. The transformation process of exchangeable fraction in soil was estimated by Elovich kinetic equation for the above incubation periods, and the constant $B$ in Elovich equation was applied to reflect the transformation rates of metal speciation. It was found that waterlogging incubation could immobilize heavy metals, resulting in decreased lability and availability of the metals in purple soil. The effect of waterlogging on the redistribution of heavy metals in purple soil might be mainly related to the changes of $\mathrm{pH}$, potential redox and hydrous oxides in varying soil-water systems.
\end{abstract}

Keywords Cadmium - Chemical speciation . Copper $\cdot$ Lead $\cdot$ Waterlogged purple soil

S. A. Zheng $(\varangle) \cdot$ X. Q. Zheng · C. Chen Agro-Environmental Protection Institute, Key Laboratory of Production Environment and Agro-Product Safety, Ministry of Agriculture, Tianjin, 300191, People's Republic of China e-mail: zhengshunan1234@qq.com

\section{Introduction}

Soils often act as a sink for heavy metals derived from various anthropogenic sources. The reactivity of trace metals in soils, in direct relation with their physicochemical form and localization in different soil components, is the main parameter ruling their bioavailability and mobility (Tack and Verloo 1995). The determination of the total concentration of metal ions in soils does not give sufficient information about mobility and bioavailability of trace metals. Sequential extraction, although operationally defined, can give information about the association of heavy metals with geochemical phases of soil, and hence helps to reveal the distribution of heavy metals infractions and to assess the mobility and toxicity of metals in soils (Amanda Jo and David 2010). Among numerous sequential extraction methods, the method proposed by Tessier et al. (1979) was most widely used. According to this protocol, metals in soil were fractionated into exchangeable, carbonate-, Fe-Mn oxide-, organic matter-bound and residue fractions. Generally, the exchangeable fractions are considered readily mobile and bioavailable, whereas other metal fractions, especially a residual fraction, are considered immobile and tightly bound and may not be expected to be released under natural conditions. Field studies prove that heavy metals added to soils are transferred with time from the soluble and exchangeable fractions into less labile fractions (Han and Banin 1999). A term that is used to indicate the increased retention of metals with aging time is fixation.

Fixation of metals takes place by the slow diffusion of metals into $\mathrm{Fe}$ oxides, hydrous oxides of $\mathrm{Al}$ and $\mathrm{Mn}$, clay minerals and by diffusion or precipitation in carbonates (Alexander 2000). Soil moisture regime is one of the most important factors for control of the physical, chemical, and 
biological properties of soil. It can affect $\mathrm{pH}$, potential redox (Eh), organic matter and $\mathrm{CaCO}_{3}$ contents of soil (Van den Berg and Loch 2000), and accordingly, may indirectly influence the transformation and repartition of heavy metals in soil, further altering their availabilities to plants.

Purple soil is the representative soil type in Sichuan province, which is the biggest province in western China with a population of over 88 million. Due to the soil background and human activities, the soil has been contaminated by heavy metals in many areas, resulting in potential risk to local human health and environment. Rice cultivation in purple soil has generally experienced rotation of waterlogged and non-waterlogged conditions to meet the need of growth, which are related to the transformation of metal fractions, and hence affect the mobility and bioavailability of heavy metals. Limited information, however, is available regarding the effect of waterlogging on the speciation changes of harmful metals in purple soil. Therefore, this study was designed to assess solid-phase transformation of added copper $(\mathrm{Cu})$, lead $(\mathrm{Pb})$, and cadmium $(\mathrm{Cd})$ during 35-day period of incubation under two moisture regimes of $80 \%$ field capacity and waterlogging in a typical Chinese purple soil, and to evaluate the extent of influence of waterlogging on the redistribution of heavy metal speciation. This work should offer a significant insight into the redistribution of freshly spiked metals among soil components regarding waterlogged situation. The whole experiment and analysis were conducted in Key Laboratory of Production Environment and Agro-product Safety, Ministry of Agriculture, Tianjin, China, from October 2010 to March 2011.

\section{Materials and methods}

\section{Description of soil samples}

The purple soil used in the study was collected from a vegetable field of Pongzhou city in Sichuan Province, China, in October 2010. It was classified as a Regosol in the Food and Agriculture Organization of the United Nations (FAO) taxonomy, which was derived from TriasCretaceous system and widely distributed in Sichuan basin located in southwestern China with an area of $165,000 \mathrm{~km}^{2}$ and an elevation varying from 200 to $500 \mathrm{~m}$ above sea level (He and Huang 1993). The climate of studied area is subtropical humid monsoon with an average annual precipitation of $1,000-1,200 \mathrm{~mm}$ and the average annual temperature is $14-19{ }^{\circ} \mathrm{C}$ (Yang 1982). More than 10 topsoil $(0-20 \mathrm{~cm})$ samples were randomly collected in the vegetable field, composited by mixing together and airdried, ground and sieved through a $2-\mathrm{mm}$ sieve. Selected soil characteristics determined by standard methods ( $\mathrm{Lu} 2000$ ) were 6.27 for $\mathrm{pH}, 0.64 \mathrm{~g} \mathrm{~kg}^{-1}$ for $\mathrm{CaCO}_{3}$, $26.51 \mathrm{~g} \mathrm{~kg}^{-1}$ for organic matter, $20.81 \mathrm{~g} \mathrm{~kg}^{-1}$ for CEC, $23.71 \mathrm{~g} \mathrm{~kg}^{-1}$ for free $\mathrm{Fe}$ oxides, $2.41 \mathrm{~g} \mathrm{~kg}^{-1}$ for amorphous Fe oxides, $265.41 \mathrm{~g} \mathrm{~kg}^{-1}$ for clay $(<0.002 \mathrm{~mm})$, $43.92 \mathrm{mg} \mathrm{kg}^{-1}$ for total lead, $51.84 \mathrm{mg} \mathrm{kg}^{-1}$ for total copper, and $0.356 \mathrm{mg} \mathrm{kg}^{-1}$ for total cadmium. Metal speciation of native soil was also determined (detailed information shown in "Results and discussion").

\section{Experimental design}

The incubation experiment was performed with $1.5 \mathrm{~kg}$ (oven-dry weight, $105^{\circ} \mathrm{C}$ ) soil sample in plastic beaker. Nitrate salts of heavy metals $\mathrm{Cu}, \mathrm{Pb}$ and $\mathrm{Cd}$ in aqueous solution were added in a single soil sample and then mixed thoroughly. The amounts of metals spiked were $500 \mathrm{mg}$ $\mathrm{kg}^{-1}$ for $\mathrm{Cu}$ and $\mathrm{Pb}, 2 \mathrm{mg} \mathrm{kg}{ }^{-1}$ for $\mathrm{Cd}$ (metal/soil), respectively, which represented the medium contaminated level according to the classifications defined by SamsoeePetersen et al. (2002) and Chinese Environmental Protection Agency (1995).

The metal-spiked soil samples were then subjected to two treatments of moisture regimes:

1. Non-waterlogging ( $80 \%$ field capacity (FC)): incubated in a moisture regime of $80 \%$ field capacity, the soil samples were weighted every day, and deionized water was added to keep the soil moisture constant.

2. Waterlogging: deionized water was added to the soil samples to form a $5-\mathrm{cm}$ layer of water over the soil samples.

During the incubation process, the plastic beakers were covered with the porous plastic membrane and placed in an incubator under the constant temperature $\left(25^{\circ} \mathrm{C}\right)$ and humidity $(80 \%)$. Each treatment was replicated in triplicate. At different incubation times, 1, 3, 7, 14 and 35 days, subsamples were taken from each beaker for the measurement of total content and speciation of heavy metals, $\mathrm{pH}$, Eh, free $\mathrm{Fe}$ oxides and amorphous Fe oxides. Prior to sampling, each soil sample was mixed completely to ensure homogeneity and representativeness. Besides, a part of the subsample from each beaker was used to determine the moisture content in order to present the data on an oven-dry weight basis.

Sequential extraction procedure

The sequential extraction proposed by Tessier et al. (1979) was employed in the current study. Chemical reagents, extraction conditions and corresponding fractions are defined as follows: 
1. Exchangeable fraction (EXC): $2 \mathrm{~g}$ of soil sample (ovendry weight, $\left.105{ }^{\circ} \mathrm{C}\right), 16 \mathrm{~mL} 1.0 \mathrm{~mol} \mathrm{~L}^{-1} \mathrm{MgCl}_{2}, \mathrm{pH}$, shake $1 \mathrm{~h}, 20^{\circ} \mathrm{C}$.

2. Carbonate-bound fraction (CAR): $16 \mathrm{~mL}$ of $\mathrm{pH} 5$, $1.0 \mathrm{~mol} \mathrm{~L}^{-1}$ sodium acetate, shake $5 \mathrm{~h}$ at $20^{\circ} \mathrm{C}$.

3. Fe-Mn oxide-bound fraction (OX): $40 \mathrm{~mL}$ of $0.04 \mathrm{~mol} \mathrm{~L}{ }^{-1} \mathrm{NH}_{4} \mathrm{OH} \cdot \mathrm{HCl}$ in $25 \%(\mathrm{v} / \mathrm{v})$ acetic acid at $\mathrm{pH} 3$ for $5 \mathrm{~h}$ at $96{ }^{\circ} \mathrm{C}$ with occasional agitation.

4. Organic matter-bound fraction $(\mathrm{OM}): 6 \mathrm{~mL}$ of $0.02 \mathrm{~mol} \mathrm{~L}^{-1} \mathrm{HNO}_{3}$ and $10 \mathrm{~mL}$ of $30 \% \mathrm{H}_{2} \mathrm{O}_{2}$ (pH adjusted to 2 with $\mathrm{HNO}_{3}$ ), water bath, $85^{\circ} \mathrm{C}$ for 5 h with occasional agitation. $10 \mathrm{~mL}$ of $3.2 \mathrm{~mol} \mathrm{~L}^{-1} \mathrm{NH}_{4} \mathrm{OAc}$ in $20 \%$ (v/v) $\mathrm{HNO}_{3}$, shake $30 \mathrm{~min}$.

5. Residual fraction (RES): Dried in a forced-air oven at $40{ }^{\circ} \mathrm{C}, 24 \mathrm{~h}$. Subsamples after sieving with $0.149 \mathrm{~mm}$ openings were used for determining $\mathrm{Cu}, \mathrm{Pb}, \mathrm{Cd}$ contents.

Extractions were conducted in $100 \mathrm{~mL}$ polypropylene centrifuge tubes. Between each successive extraction, the supernatant was centrifuged at $4,000 \mathrm{rpm}$ for $30 \mathrm{~min}$ and then filtered.

Metal determination and quality control

Total and residual fraction of $\mathrm{Cu}, \mathrm{Pb}$ and $\mathrm{Cd}$ in soil were determined by digesting $0.5 \mathrm{~g}$ soil samples (oven-dry weight, $105^{\circ} \mathrm{C}$ ) with $\mathrm{HNO}_{3} \cdot \mathrm{HF} \cdot \mathrm{HClO}_{4}$ mixture followed by elemental analysis. The concentrations of $\mathrm{Cu}, \mathrm{Pb}$ and $\mathrm{Cd}$ in all solutions were analyzed by an atomic absorption spectrophotometer (AA220Z, Varian, USA). Nitrates of heavy metals were analytical grade. Digestion acids were guaranteed reagent. Ultrapure water was obtained from a Milli-Q system (Quantum EX, Millipore, USA). All containers were soaked in $10 \% \mathrm{HCl}$, rinsed thoroughly in deionised water and dried out before use. The standard substances (geochemical standard reference sample soil in China, GSS-1) were used to examine the precision and accuracy of determination. As a check for the reliability of sequential extraction procedure, the relative errors (REs) between the sum of the metal concentration in individual fractions and the measured total metal concentration in soil samples were calculated and ranged from -12.1 to $9.4 \%$, and the sums of extracted metal fractions over the experimental period were fairly constant (coefficients of variation, $\mathrm{CV}<12.5 \%$ ). Therefore, it is more convenient to use fractional distribution patterns to study the redistribution of metals with time, and the percentages of metals in different fractions were used to reflect the metal redistribution in the incubated soil samples in the study.

\section{Statistical analysis}

One-way analysis of variance (ANOVA) were performed at $5 \%$ level to determine whether there were significant differences in changes of metal fractions and soil properties during incubation time between $80 \%$ field capacity and waterlogging. Statistical analysis and model fit were performed using the software of SPSS 17.0 for windows.

\section{Results and discussion}

Distribution of background heavy metals in native soil

The fraction of each background metal in native purple soil is presented in Fig. 1. In the native soil, the dominating chemical form for $\mathrm{Cu}$ was the RES $(68.57 \%$ on an average, the same follows). Its association in the non-residual fraction was in the order: OM $(14.63 \%)>\mathrm{OX}(8.17 \%)$, > CAR $(5.98 \%)>\operatorname{EXC}(2.65 \%)$. Pb in native purple soil showed the order of association: RES $(75.62 \%)>$ OX $(11.65 \%)>\mathrm{OM}(5.62 \%)$ and $\operatorname{CAR}(5.57 \%)>\mathrm{EXC}$ $(1.54 \%)$. The $\mathrm{Cd}$ association with different fractions in native purple soil followed the order: RES $(59.35 \%)>$ OX $(13.62 \%)>$ CAR $\quad(10.68 \%)>$ OM $\quad(7.76 \%)>$ EXC $(8.59 \%)$. The high percentage of heavy metals in the residual fraction in unpolluted soils has been observed by many studies (Kashem et al. 2007; Jalali and Khanlari 2008). Exchangeable fractions accounted for a very low percentage of $\mathrm{Cu}$ and $\mathrm{Pb}$ which were in agreement with the previous studies of Ma and Rao (1997) and Ramos et al. (1994). In the non-residual fractions the relative high percentage of $\mathrm{Cd}$ was associated with the exchangeable fraction, which is in agreement with the findings (Kim and Owens 2009; Tang et al. 2006) that Cd usually was present more labile in soils.

Transformation of spiked metals in purple soil

Figure 2 shows the time-dependent fraction transformations of $\mathrm{Cu}, \mathrm{Pb}$, and $\mathrm{Cd}$ in purple soil incubated from 1 to 35 days. There were some clear and major differences between the distributions of indigenous and spiked metals in purple soil. In the case of indigenous metals, the proportions present as EXC fractions were very low for all

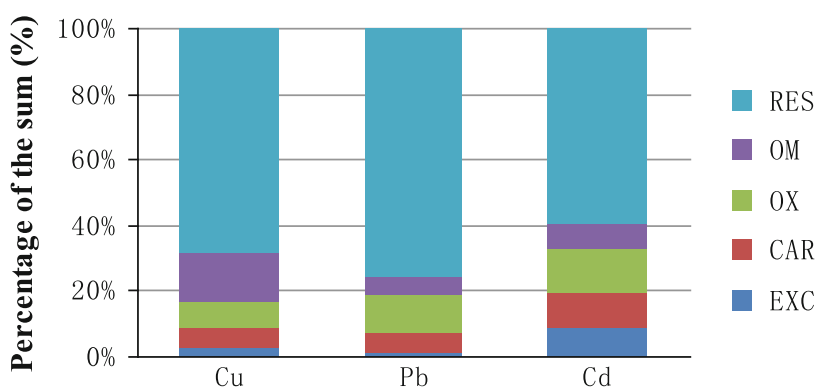

Fig. 1 Fractionation of background heavy metals in native purple soil 


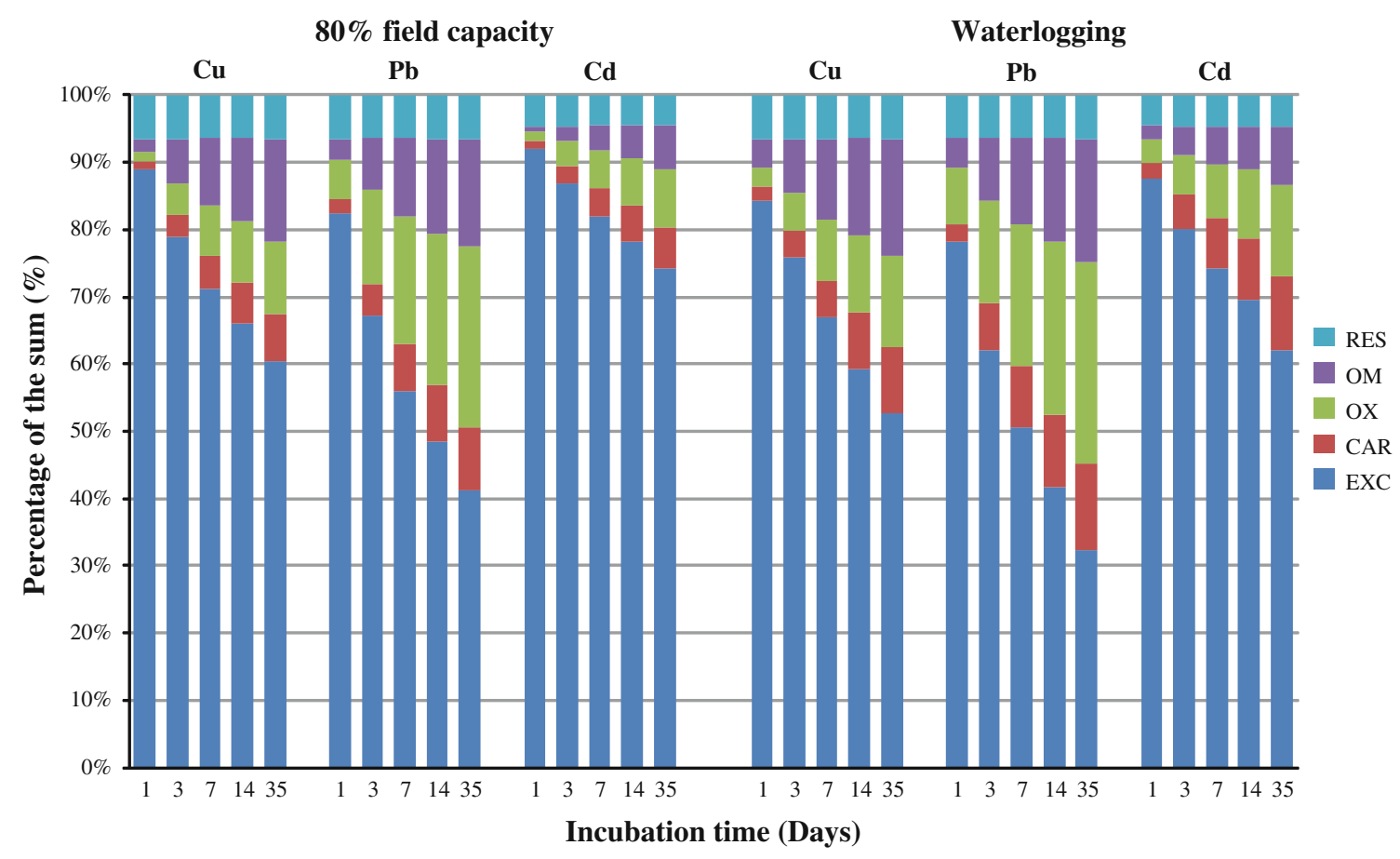

Fig. 2 Fractionation of spiked metals in purple soil as a function of incubation time

moisture regimes in purple soil, with the bulk of the metals distributed between RES, OX, CAR and OM fractions. As for spiked metals, it was supposed that at the time zero of the incubation period, almost all the newly added heavy metals existed either in the soil solution or in the surface of soil particles (e.g. EXC fraction). When the incubation time was prolonged, the EXC fractions of heavy metals decreased significantly and consistently in purple soil under all treatments. By the time of first sampling (1st day), the proportions of the EXC fractions at $80 \%$ field capacity regime were $89.03 \%$ for $\mathrm{Cu}, 82.37 \%$ for $\mathrm{Pb}$ and $92.02 \%$ for $\mathrm{Cd}$, while those at waterlogging regime were $84.28 \%$ for $\mathrm{Cu}, 78.09 \%$ for $\mathrm{Pb}$ and $87.48 \%$ for $\mathrm{Cd}$. From 1 to 35 days of incubation, the proportions of exchangeable $\mathrm{Cu}$, $\mathrm{Pb}$ and $\mathrm{Cd}$ at $80 \%$ field capacity regime in purple soil decreased by more than 27,40 and $17 \%$, respectively, while those at waterlogging regime decreased by more than 32, 46 and $26 \%$, respectively. The decreases of exchangeable heavy metals were particularly noticeable in waterlogged purple soil $(p<0.05)$. After 35-day incubation, the exchangeable fractions of heavy metals in purple soil decreased to the relatively lower degrees, where were $60.48 \%$ for $\mathrm{Cu}, 41.31 \%$ for $\mathrm{Pb}$ and $74.11 \%$ for $\mathrm{Cd}$ at $80 \%$ field capacity regime, and $52.70 \%$ for $\mathrm{Cu}, 32.39 \%$ for $\mathrm{Pb}$ and $61.94 \%$ for $\mathrm{Cd}$ at waterlogging regime.

The proportions of spiked metals bound to carbonate and $\mathrm{Fe}-\mathrm{Mn}$ oxides increased consistently with increasing incubation time, especially in waterlogged soil. After 35-day of incubation, the proportions of $\mathrm{Cu}, \mathrm{Pb}$ and $\mathrm{Cd}$ in the CAR fractions accounted for 7.04, 9.26 and $6.08 \%$, respectively, at $80 \%$ field capacity regime, whereas those were $9.72,12.82$ and $11.23 \%$, respectively, at waterlogging regime; oxide-bound fractions of the heavy metals occupied $10.71 \%$ of the spiked $\mathrm{Cu}, 26.90 \%$ of the spiked $\mathrm{Pb}, 8.72 \%$ of the spiked $\mathrm{Cd}$ at $80 \%$ field capacity regime, while those were $13.70 \%$ for $\mathrm{Cu}, 29.83 \%$ for $\mathrm{Pb}$ and $13.44 \%$ for $\mathrm{Cd}$ at waterlogging regime. The change patterns of the organic matter-bound fractions of spiked metals were similar to those of the carbonate and oxidebound fractions in treated purple soil. Up to 35 days of incubation, the proportions of metals bound to organic matter reached $15.20 \%$ for $\mathrm{Cu}, 15.99 \%$ for $\mathrm{Pb}$ and $6.52 \%$ for $\mathrm{Cd}$ at $80 \%$ field capacity regime, whereas those were $17.40 \%$ for $\mathrm{Cu}, 18.40 \%$ for $\mathrm{Pb}$ and $8.58 \%$ for $\mathrm{Cd}$ at waterlogging regime. The proportions of the metal residual fractions in spiked-soil accounted for on an average $6.56 \%$ for $\mathrm{Cu}, 6.39 \%$ for $\mathrm{Pb}$ and $4.43 \%$ for $\mathrm{Cd}$ in treated purple soils. Statistical analyses confirmed that the concentration of the residual fraction of each metal in spiked-soil under all treatments was consistent to that in native soil, and remained almost unchanged during the whole incubation period $(p<0.05)$.

The above results indicated that, through the incubation period, spiked heavy metals transformed slowly from the EXC fraction into the CAR, OX and OM fractions. Accordingly, the metals added in soluble form were gradually transferred from the more labile fractions into the more stable fractions. These metals might be retained by 
Fig. 3 Decrease of $\mathrm{Cu}, \mathrm{Pb}$, and $\mathrm{Cd}$ in EXC fraction as a function of the natural logarithm of incubation time

\section{$\mathbf{P b}$}

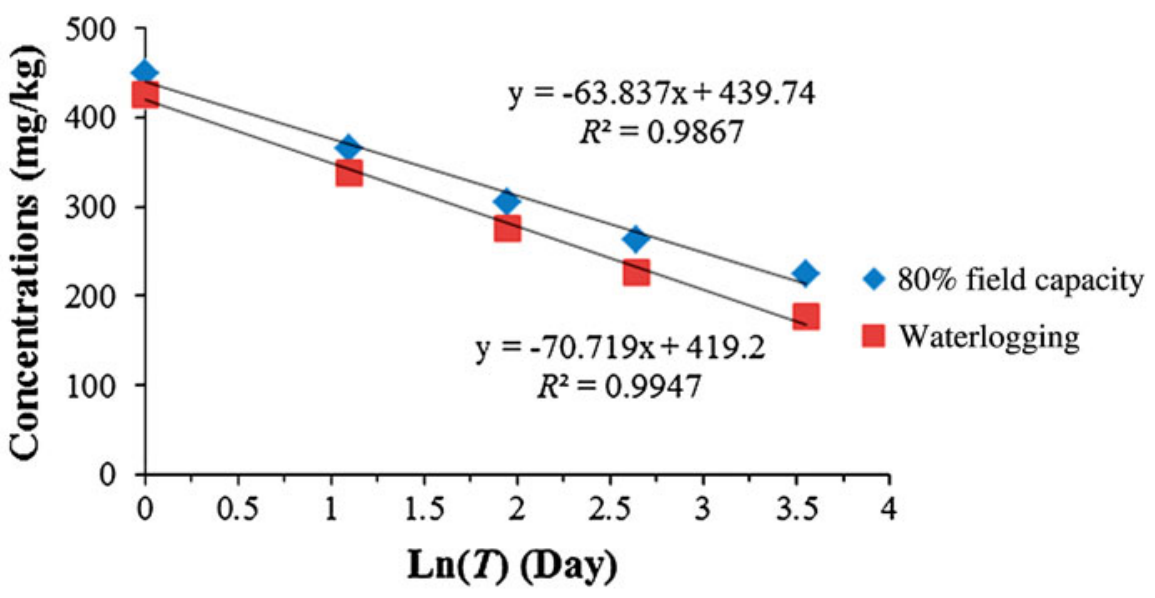

$\mathrm{Cu}$

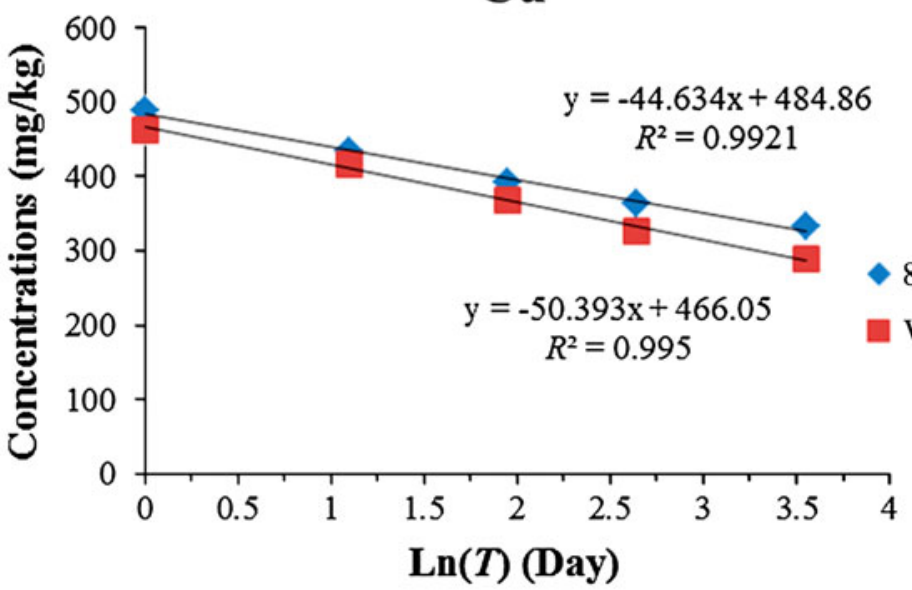

$80 \%$ field capacity

Waterlogging

Cd

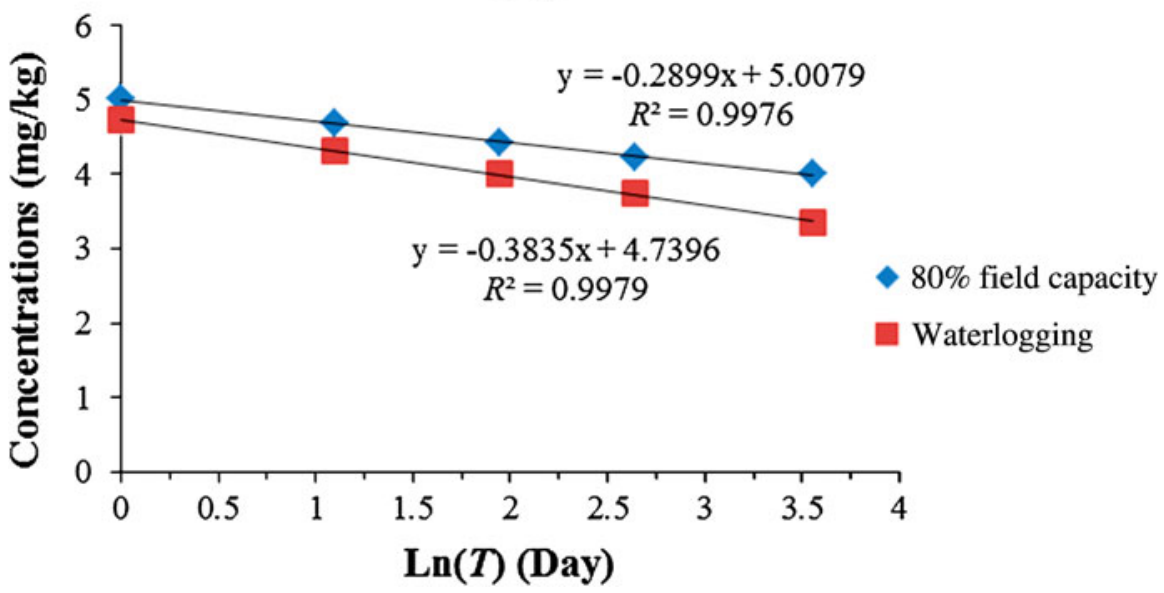

soil components in the near surface soil horizons or could precipitate and/or co-precipitate as sulfides, carbonates, oxides or hydroxides. No significant differences in the metal concentrations of the RES fraction were observed in soil samples, which meant the added metals hardly entered the crystalline lattice over 35-day incubation. On the other hand, there were clear differences in the rates of the proportional distribution of $\mathrm{Cu}, \mathrm{Pb}$, and $\mathrm{Cd}$ in purple soil treated with two moisture regimes during the 35 days of incubation with spiked heavy metals, at which 
Table 1 Soil properties under two moisture regimes after 35-day incubation (means of triplicate)

\begin{tabular}{lllll}
\hline Moisture regimes & $\mathrm{pH}$ & Eh $(\mathrm{mV})$ & Free Fe oxides $\left(\mathrm{g} \mathrm{kg}^{-1}\right)$ & Amorphous Fe oxides $\left(\mathrm{g} \mathrm{kg}^{-1}\right)$ \\
\hline $80 \%$ field capacity & $6.43 \mathrm{~b}^{*}$ & $250 \mathrm{a}$ & $23.89 \mathrm{a}$ & $2.39 \mathrm{~b}$ \\
Waterlogging & $6.90 \mathrm{a}$ & $-190 \mathrm{~b}$ & $22.21 \mathrm{a}$ & $7.21 \mathrm{a}$ \\
\hline
\end{tabular}

* Comparison between means was made with the one-way ANOVA test. Different letters in a same column indicated a significant difference between moisture regimes at $p<0.05$

redistribution took place with the changes occurring generally faster in the waterlogged soil as compared to the other soil treated with $80 \%$ field capacity regime.

Transformation rate of spiked metals in purple soil

The exchangeable form is considered readily mobile and easily bioavailable, and thus it deserves a serious concern. As mentioned above, it was clear that the exchangeable metal concentrations decreased consistently with incubation time. By plotting the metal concentration in EXC fraction against the natural logarithm of incubation time, a linear regression equation could be simulated as follows:

$C_{m}=A+B \operatorname{Ln}(T)$

where $C_{m}$ is the metal concentration $\left(\mathrm{mg} \mathrm{kg}^{-1}\right)$ in the EXC fraction, $A$ and $B$ are constants relate to the properties of soil and heavy metals, and $T$ is incubation time (Day). As illustrated in Fig. 3, the coefficients of determination $\left(R^{2}\right)$ from 0.9867 to $0.9979(n=5, p<0.05)$, which manifested the linear fits were satisfactory.

The Eq. 1 fitted well to experimental data demonstrated that the overall decrease rate of the exchangeable metal can be simulated by the Elovich kinetic model. The constant $A$ reflected the concentration of exchangeable metal fraction in day 1 after exogenous metal spiked in soil. The constant $B$ in Elovich equation reflected the transformation rate of metal speciation from the exchangeable fraction toward stable fractions, which can be used as an index of transformation rates. By judging this parameter for three elements under two moisture regimes, the following order was founded: $\mathrm{Pb}>\mathrm{Cu}>\mathrm{Cd}$, which coincided with the result by $\mathrm{Lu}$ et al. (2005) that the decrease in transformation rate followed the order $\mathrm{Pb}>\mathrm{Cu}>\mathrm{Zn}>\mathrm{Cd}$, indicating Cd's lability in the soil and the lack of strong binding mechanisms for this metal to the solid-phase of soil. Furthermore, it was also clearly that spiked metals under waterlogging regime had relatively higher transformation rates by contrast with $80 \%$ field capacity regime, resulting in the more complete movement of these metals from the exchangeable fraction toward stable fractions (CAR, OX and $\mathrm{OM}$ ) in waterlogged purple soil.
Effect of waterlogging on metal speciation

The effect of waterlogging on the redistribution of heavy metals in purple soil might be mainly related to the changes of $\mathrm{pH}$, Eh and hydrous oxides in varying soil-water systems.

When oxidized purple soil samples were submerged, biological and microbiological activities combined with limited oxygen diffusion, which caused oxygen depletion and established reducing conditions, where an observable change, namely, a decrease of Eh associated with an increase of $\mathrm{pH}$ towards neutrality would follow (Chuan et al. 1996) (Table 1).

Under flooding regime, waterlogging contributes to increased $\mathrm{pH}$. This change may result in more negative charges on soil clay colloids and organic matter surfaces, and correspondingly decrease the exchangeable heavy metals by immobilization over these surfaces (Yuan and Lavkulich 1997; Zhang et al. 1997). Lim et al. (2002) investigated the changes of speciation of $\mathrm{Pb}$ and $\mathrm{Cd}$ in soil at various $\mathrm{pH}$ values with different time and found that the changes of $\mathrm{Pb}$ and $\mathrm{Cd}$ in exchangeable fraction were $\mathrm{pH}-$ dependent. By monitoring the process of heavy metals on iron oxide ( $\alpha-\mathrm{FeOOH})$, Martínez and Mcbride (2001) found that either adsorption or co-precipitation of heavy metals with ferrihydrite was $\mathrm{pH}$-dependent. They also found that the increasing $\mathrm{pH}$ and incubation time resulted in the increase of adsorption and co-precipitation of heavy metals. On the other hand, increased concentrations of OM-bound $\mathrm{Cu}, \mathrm{Pb}$, and $\mathrm{Cd}$ fractions in the waterlogged soil, as compared with non-flooded soil, was perhaps due to metalorganic complex formation, which has higher magnitude in the waterlogged soils because lower values of Eh and higher values of $\mathrm{pH}$ in this system were propitious to the formation of metal-organic complexes (Gambrell 1994) and microbial immobilization (Haldar and Mandal 1979). Particularly, metal bound to carbonate in soil is more susceptible to $\mathrm{pH}$ increase (Martínez and Motto 2000), which could explain the metal concentrations of CAR fractions increased under waterlogging treatment. These $\mathrm{pH}$-dependent mechanisms might have taken place in the waterlogged soil to immobilize heavy metals in the study. 
Waterlogging also affected the crystallization of $\mathrm{Fe}$ oxides in the soils (Table 1). After 35-day incubation, concentration of amorphous $\mathrm{Fe}$ oxides in waterlogged soil increased by three times than that at $80 \%$ field capacity moisture regime, while the concentrations of free Fe oxides did not differ significantly between two soil moisture regimes. In waterlogged soil, reducing conditions would cause the oxides of $\mathrm{Fe}$ and $\mathrm{Mn}$ in soil solid phases to be reduced and dissolved. Reduced Fe and Mn via hydrolysis and oxidation precipitate as highly as amorphous hydrous oxides that have a strong sorption capacity for trace elements. The X-ray amorphous hydrated oxides and oxides with a low crystallinity showed a larger adsorption capability for heavy metal cations than those with a high crystallinity (Okazaki et al. 1986). As a result, this process decreased concentrations of $\mathrm{Cu}, \mathrm{Pb}$ and $\mathrm{Cd}$ in the EXC fractions, and increased their $\mathrm{OX}$ fractions in the waterlogged soil correspondingly (Fig. 2). This was also observed by Kashem and Singh (2004). In their findings, the breakdown of $\mathrm{Fe}$ and $\mathrm{Mn}$ oxides caused by water logging provided, on one hand, surfaces with high adsorbing capacity for $\mathrm{Cd}$ and $\mathrm{Zn}$, but, on the other hand, increased the concentration of $\mathrm{Fe}$ and $\mathrm{Mn}$ in the mobile fraction. They (Kashem and Singh 2001) suggested that adsorption of trace metals on Fe-Mn oxyhydroxide fractions was the major mechanism of their solubility reduction in submerged conditions. Furthermore, microbial immobilizations and antagonistic and/or competitive effects of increased concentrations of $\mathrm{Fe}, \mathrm{Mn}$ and $\mathrm{P}$ have also been suggested as possible reasons for the decreased exchangeable metals in waterlogged soils (Haldar and Mandal 1979; Nwuche and Ugoji 2008).

The $\mathrm{OM}$ fractions of $\mathrm{Cu}, \mathrm{Pb}$ and $\mathrm{Cd}$ in waterlogged soil increased significantly (Fig. 2), perhaps due to the metalorganic complex formation. As known, metals are more tightly bound by organics under anoxic conditions, compared with oxic conditions where degraded sediment material has a tendency to decrease and the humic materials may become structurally less complex (Gambrell 1994).

In addition, insoluble sulfide forms of metals would generate in reductive conditions driven by flooding, which could be one of the reasons why heavy metals exhibit low mobility in waterlogged soil. Most metal sulfides are highly insoluble, and under the indirect effects of flooding conditions (low Eh), sulfate ions are reduced to the sulfide form, which might form a complex with heavy metals and immobilize them as sulfide salts (Van den Berg et al. 1998).

\section{Conclusion}

Heavy metals $\mathrm{Cu}, \mathrm{Pb}$, and $\mathrm{Cd}$ added to a Chinese purple soil in soluble form at $80 \%$ field capacity and waterlogging regimes were transformed slowly from the exchangeable fractions into more stable fractions, whereas their residual fractions barely changed. Metals in exchangeable fraction decreased with time and such decreases could be simulated by an Elovich kinetic equation. Besides, the transformations of $\mathrm{Cu}, \mathrm{Pb}$ and $\mathrm{Cd}$ from the EXC fraction into other fractions during the incubation period was relatively easier in the waterlogged purple soil as compared with $80 \%$ field capacity regime, resulting in the more complete movement of these metals toward stable fractions.

Acknowledgments This work was financially supported by National Department (Agriculture) Public Benefit Research Foundation (200903015) and Central Public Research Institutes Basic Funds for Research and Development (Agro-Environmental Protection Institute, Ministry of Agriculture).

\section{References}

Alexander M (2000) Aging, bioavailability, and overestimation of risk from environmental pollutants. Environ Sci Technol 34(20):4259-4265

Amanda Jo Z, David C (2010) Heavy Metal and trace metal analysis in soil by sequential extraction: a review of procedures. Int $\mathrm{J}$ Environ Anal Ch 2010:1-7

Chinese Environmental Protection Agency (1995). Environmental quality standard for soil. GB 15168-1995

Chuan MC, Shu GY, Liu JC (1996) Solubility of heavy metals in a contaminated soil: effects of redox potential and $\mathrm{pH}$. Water Air Soil Poll 90(3):543-556

Gambrell RP (1994) Trace and toxic metals in wetlands: a review. J Environ Qual 23(5):883-891

Haldar M, Mandal LN (1979) Influence of soil moisture regimes and organic matter application on the extractable $\mathrm{Zn}$ and $\mathrm{Cu}$ content in rice soils. Plant Soil 53(1):203-213

Han FX, Banin A (1999) Long-term transformation and redistribution of potentially toxic heavy metals in arid-zone soils: II. Incubation at the field capacity moisture content. Water Air Soil Poll 114(3):221-250

He MR, Huang CY (1993) Purple soil degradation and its control in Sichuan province. J Mountain Sci 11(4):209-215

Jalali M, Khanlari ZV (2008) Effect of aging process on the fractionation of heavy metals in some calcareous soils of Iran. Geoderma 143(1-2):26-40

Kashem MA, Singh BR (2001) Metal availability in contaminated soils: I. Effects of flooding and organic matter on changes in Eh, $\mathrm{pH}$ and solubility of $\mathrm{Cd}, \mathrm{Ni}$ and $\mathrm{Zn}$. Nutr Cycl Agroecosys 61(3):247-255

Kashem MA, Singh BR (2004) Transformations in solid phase species of metals as affected by flooding and organic matter. Commun Soil Sci Plan 35(9):1435-1456

Kashem MA, Singh BR, Kondo T, Imamul Huq SM, Kawai S (2007) Comparison of extractability of $\mathrm{Cd}, \mathrm{Cu}, \mathrm{Pb}$ and $\mathrm{Zn}$ with sequential extraction in contaminated and non-contaminated soils. Int J Environ Sci Tech 4(2):169-176

Kim KR, Owens G (2009) Chemodynamics of heavy metals in longterm contaminated soils: metal speciation in soil solution. J Environ Sci 21(11):1532-1540

Lim TT, Tay JH, Teh CI (2002) Contamination time effect on lead and cadmium fractionation in a tropical coastal clay. J Environ Qual 31(3):806-881 
Lu RK (2000) Methods of soil and agrochemical analysis (in Chinese). China Agricultural Science and Technology Press, Beijing

Lu AX, Zhang SZ, Shan XQ (2005) Time effect on the fractionation of heavy metals in soils. Geoderma 125(3-4):225-234

Ma LQ, Rao GN (1997) Chemical fractionation of cadmium, copper, nickel, and zinc in contaminated soils. J Environ Qual 26(1):259-264

Martínez CE, McBride MB (2001) Cd, Cu, Pb, and Zn coprecipitates in $\mathrm{Fe}$ oxide formed at different $\mathrm{pH}$ : aging effects on metal solubility and extractability by citrate. Environ Toxicol Chem 20(1):122-126

Martínez CE, Motto HL (2000) Solubility of lead, zinc and copper added to mineral soils. Environ Pollut 107(1):153-158

Nwuche CO, Ugoji EO (2008) Effects of heavy metal pollution on the soil microbial activity. Int J Environ Sci Tech 5(3):409-414

Okazaki M, Takamidoh K, Yamane I (1986) Adsorption of heavy metal cations on hydrated oxides and oxides of iron and aluminum with different crystallinities. Soil Sci Plant Nutr 32(4):523-533

Ramos L, Hernandez LM, Gonzalez MJ (1994) Sequential fractionation of copper, lead, cadmium and zinc in soils from or near Donana National Park. J Environ Qual 23(1):50-57

Samsoee-Petersen L, Larsen EH, Larsen PB, Bruun P (2002) Uptake of trace elements and PAHs by fruit and vegetables from contaminated soils. Environ Sci Technol 36(14):3057-3063
Tack F, Verloo MG (1995) Chemical speciation and fractionation in soil and sediment heavy metal analysis: a review. Int J Environ Anal Chem 59(2):225-238

Tang XY, Zhu YG, Cui YS, Duan J, Tang L (2006) The effect of ageing on the bioaccessibility and fractionation of cadmium in some typical soils of China. Environ Int 32(5):682-689

Tessier A, Campbell P, Bisson M (1979) Sequential extraction procedure for the speciation of particulate trace metals. Anal Chem 51(7):844-851

Van den Berg GA, Loch J (2000) Decalcification of soils subject to periodic waterlogging. Eur J Soil Sci 51(1):27-33

Van den Berg GA, Loch J, Winkels HJ (1998) Effect of fluctuating hydrological conditions on the mobility of heavy metals in soils of a freshwater estuary in the Netherlands. Water Air Soil Poll 102(3):377-388

Yang ZG (1982) Sichuan geography (In Chinese). Press of Northeast Normal University, Chongqing

Yuan G, Lavkulich LM (1997) Sorption behavior of copper, zinc, and cadmium in response to simulated changes in soil properties. Commun Soil Sci Plan 28(6):571-587

Zhang M, Alva AK, Li YC, Calvert DV (1997) Chemical association of $\mathrm{Cu}, \mathrm{Zn}, \mathrm{Mn}$, and $\mathrm{Pb}$ in selected sandy citrus soils. Soil Sci 162(3):181-188 